\title{
Digital Classification of Land Use/ Land Cover by Using Remote Sensing Techniques
}

\author{
Dr. S.S. Manugula \\ Professor, Department of Civil Engineering, Guru Nanak Institutions, Hyderabad, Telangana, India. \\ M Sagar \\ Department of Civil Engineering, Guru Nanak Institutions, Hyderabad, Telangana, India. \\ Khambampati Sai Nihar \\ Department of Civil Engineering, Guru Nanak Institutions, Hyderabad, Telangana, India. \\ Katipelli Anudeep Reddy \\ Department of Civil Engineering, Guru Nanak Institutions, Hyderabad, Telangana, India.
}

\begin{abstract}
The landuse/landcover pattern of a region is an outcome of natural and socio-economic factors and their utilization by man in time and space. The terms "land use" and "land cover" are often used simultaneously to describe maps that provide information about the types of features found on the earth's surface is called as land cover and the human activity that is associate with them.

The social and economic development of our country is interlaced with our natural resources, and the manner in which they are managed and exploited. The finite land, minerals, water are currently under tremendous pressure in the context of highly competing, and often conflicting demands of an increasing population. So there is an urgent need to improve the productivity and the environment to meet the basic requirements of our growing population and to improve the quality of life.

The input data used in this work is satellite Image Resource Sat 2 with LISS 4 Sensor of $5 \mathrm{~m}$ resolution, and SOI toposheet. The methodology adopted for this thesis is total enumerated through digital analysis which was carried out with the help of Erdas Imagine and GIS software.
\end{abstract}

Key words- LU/LC, satellite image, Erdas Imagine, GIS, SOI.

\section{INTRODUCTION}

One of the main purposes of satellite remote sensing is to interpret the observed data and classify features. In addition to the approach of photointerpretation, quantitative analysis, which uses computer to label each pixel to particular spectral classes (called classification), is commonly used. Quantitative analysis can perform true multispectral analysis, make use of all the available brightness levels and obtain high quantitative accuracy.

There are two broads of classification procedures: supervised classification unsupervised classification. The supervised classification is the essential tool used for extracting quantitative information from remotely sensed image data [Richards, 1993, p85]. Using this method, the analyst has available sufficient known pixels to generate representative parameters for each class of interest. This step is called training. Once trained, the classifier is then used to attach labels to all the image pixels according to the trained parameters. The most commonly used supervised classification is maximum likelihood classification (MLC), which assumes that each spectral class can be described by a multivariate normal distribution. Therefore, MCL takes advantage of both the mean vectors and the multivariate spreads of each class, and can identify those elongated classes. However, the effectiveness of maximum likelihood classification depends on reasonably accurate estimation of the mean vector $\mathrm{m}$ and the covariance matrix for each spectral class data [Richards, 1993, p189]. 


\section{OBJECTIVE OF THE PROJECT}

The main objective of the project is to

i) Geo referencing of toposheet

ii) Landuse / land cover classification

iii) Accuracy Assessment / Field verification

A. Study Area
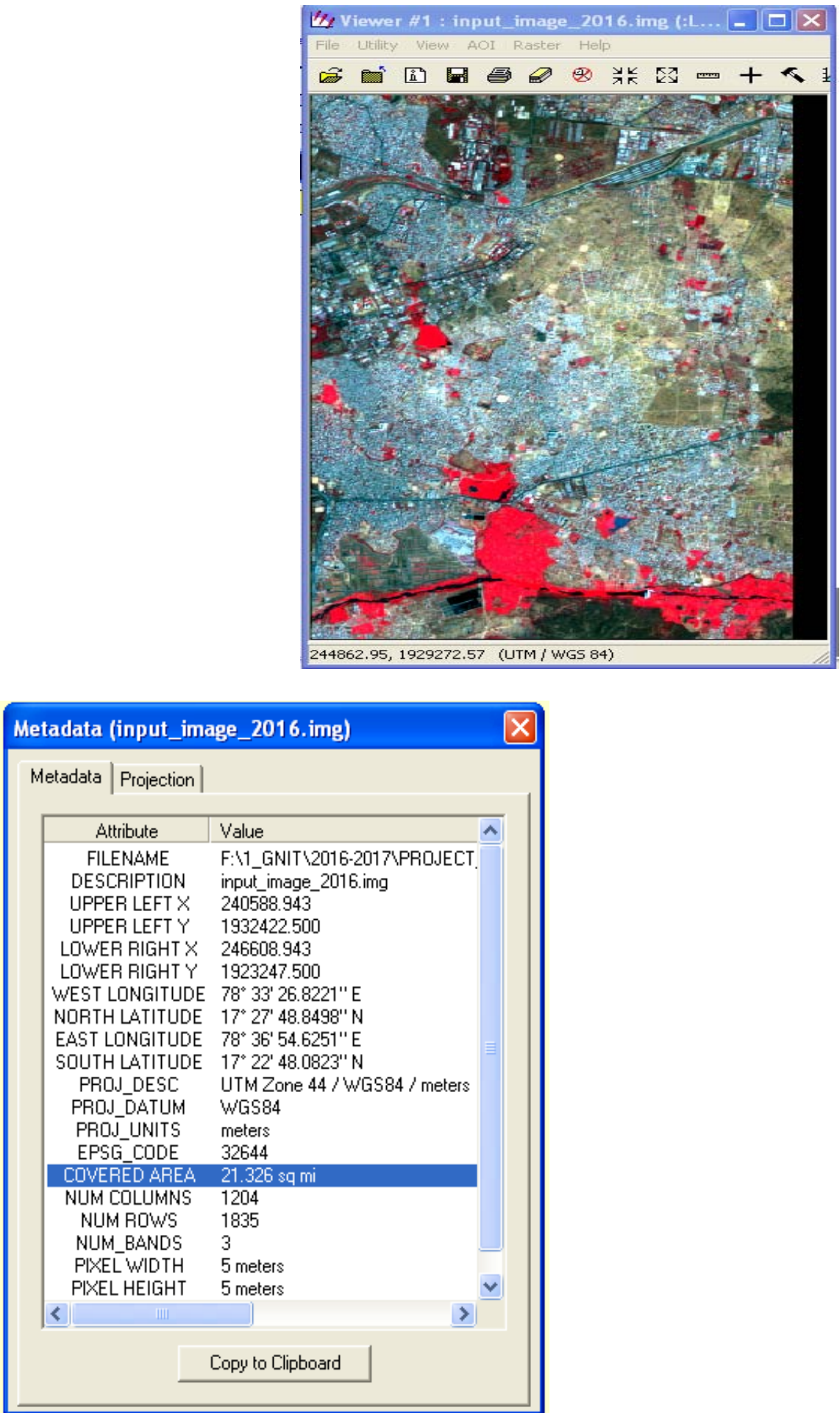

The study area is located in Cherlapally, Hyderabad

District with Latitude: $17^{\circ} 23.043^{\prime} \mathrm{N}$, Longitude: $78^{\circ} 27.38^{\prime} \mathrm{E}$ 
$>$ AOI: - 21.32 Sq mi.

The coordinates of the study area are as follows as shown in meta data

Figure 1 Satellite data

B. Data used:

The input data used in this work is

Satellite Image ie (Resource Sat 2) with LISS 4 Sensor,

SOI toposheet No 56K/11

Hand GPS Instrument (Garmin Etrex)

\section{METHODOLOGY}

\section{A. SUPERVISED CLASSIFICATION}

The following are the important aspects of supervised classification which is considered

$\checkmark \quad$ An appropriate classification scheme is adopted.

$\checkmark$ Representative training sets is selected, including an appreciation for signature extension factors, if possible.

$\checkmark \quad$ Statistics is extracted from the training sets spectral data

$\checkmark$ The statistic are analyzed to select the appropriate features to be used in the classification process.

$\checkmark$ Selected the appropriate classification algorithm

$\checkmark$ Classify the imagery into m classes based on the Visual interpretation. $\quad$ Figure 2 Meta data

$\checkmark$ Statistically evaluate the classification accuracy.

$\checkmark$ Among the above aspects representing training sites are important

$\checkmark$ Once a set of reliable signatures has been created, the next step is to perform classification of data. Each pixel is analyzed independently. The measurement vector for each pixel is compared to each signature, according to a decision rule are then assigned to the class for that signature.

\section{B. MAXIMUM LIKEHOOD}

The maximum likelihood decision rule is based on the probability that a pixel belongs to a particular class. The basic equation assumes that these probabilities are equal for all classes, and that the input bands have normal distribution.

$\mathrm{D}=[-0.5 \log \{\operatorname{det}(\mathrm{Vc})\}]-[0.5(\mathrm{X}-\mathrm{Mc}) \mathrm{T}(\mathrm{Vc})-1(\mathrm{X}-\mathrm{Mc})]$

$\mathrm{Vc}=$ covariance matrix of class 'c'

$\mathrm{X}=$ measurement vector of a pixel.

$\mathrm{Mc}=$ mean vector of class ' $\mathrm{c}$ '

\section{GEOREFERENCING}

is the process of assigning real-world coordinates to each pixel of the raster. Many times these coordinates are obtained by doing field surveys - collecting coordinates with a GPS device for few easily identifiable features in the image or map 


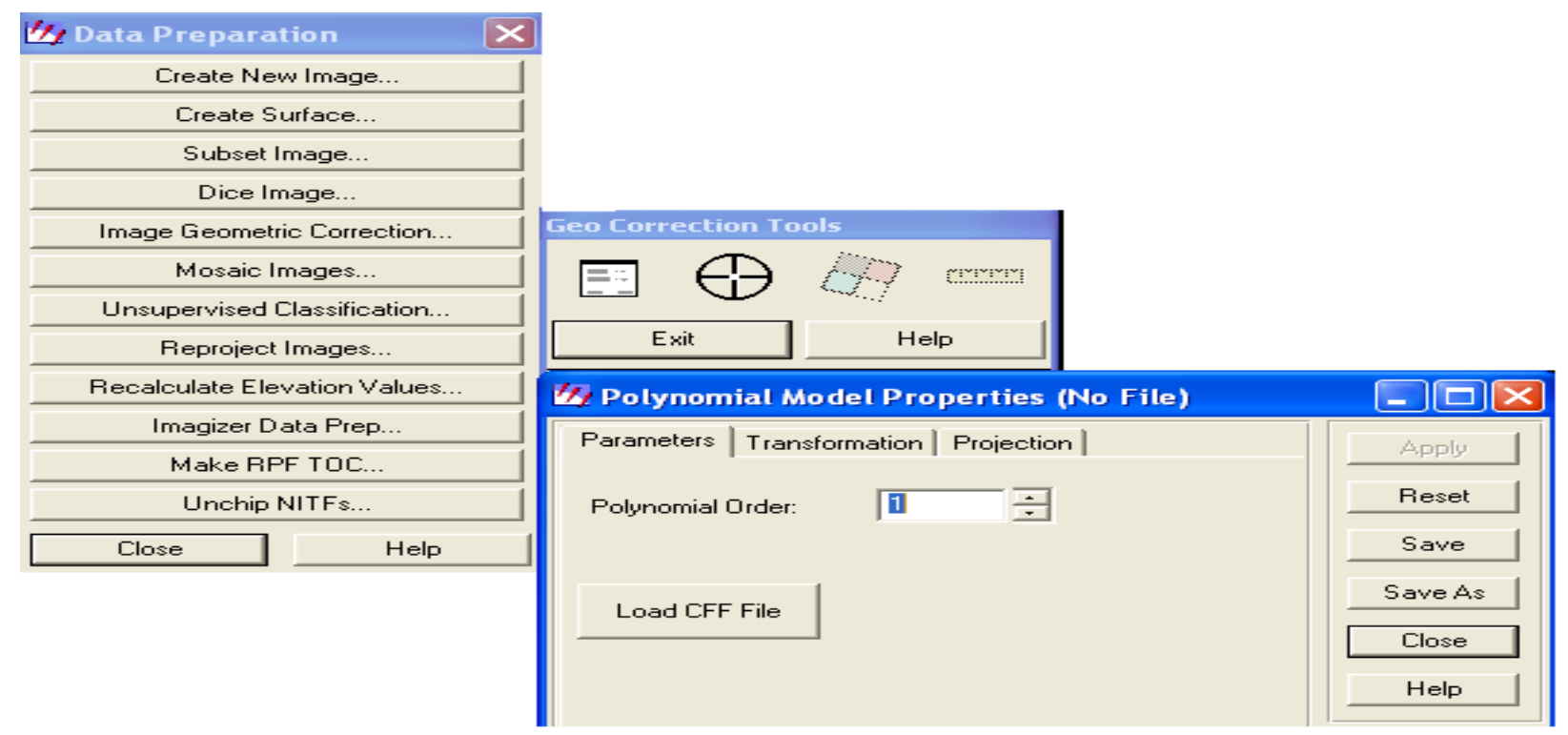

Figure 3 Image Geometric Correction

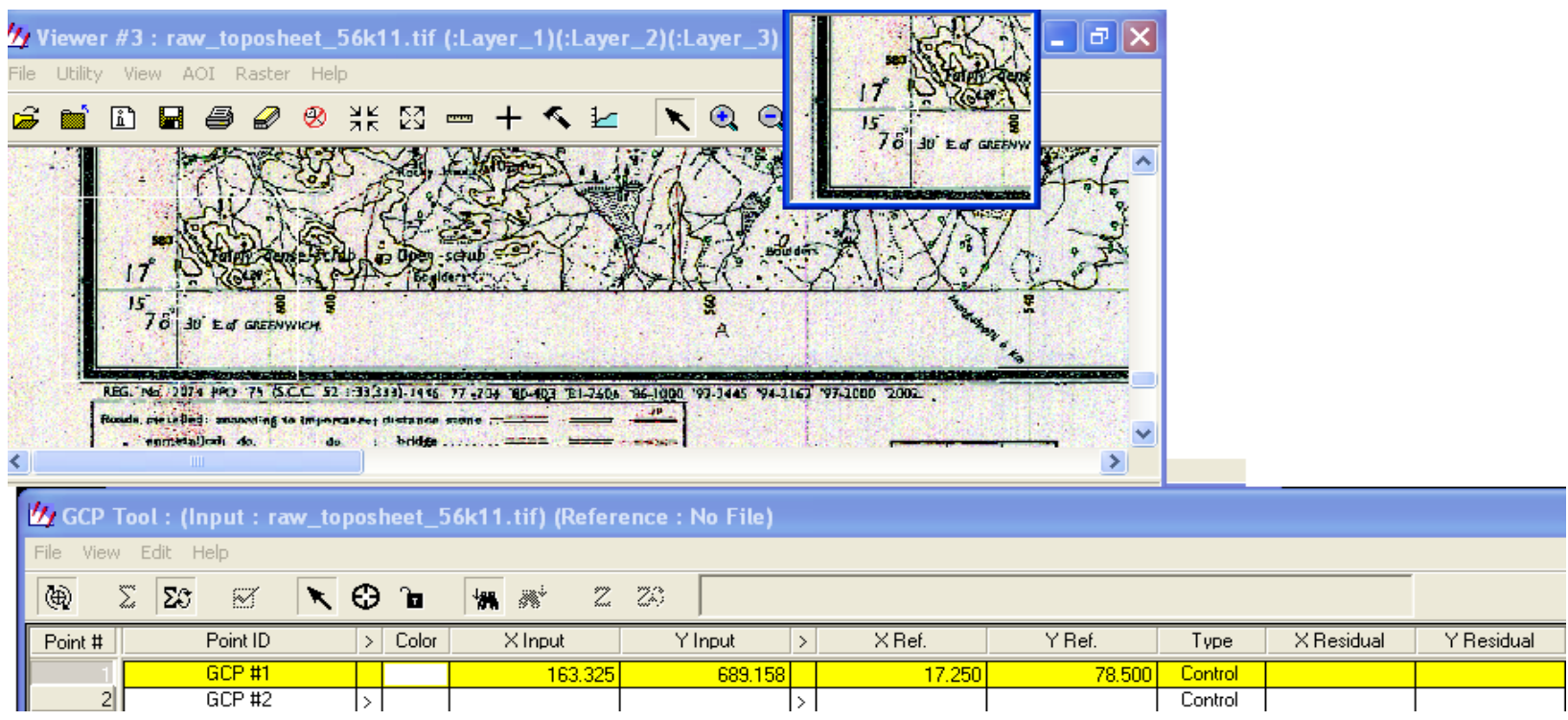

Figure 4 Image GCP

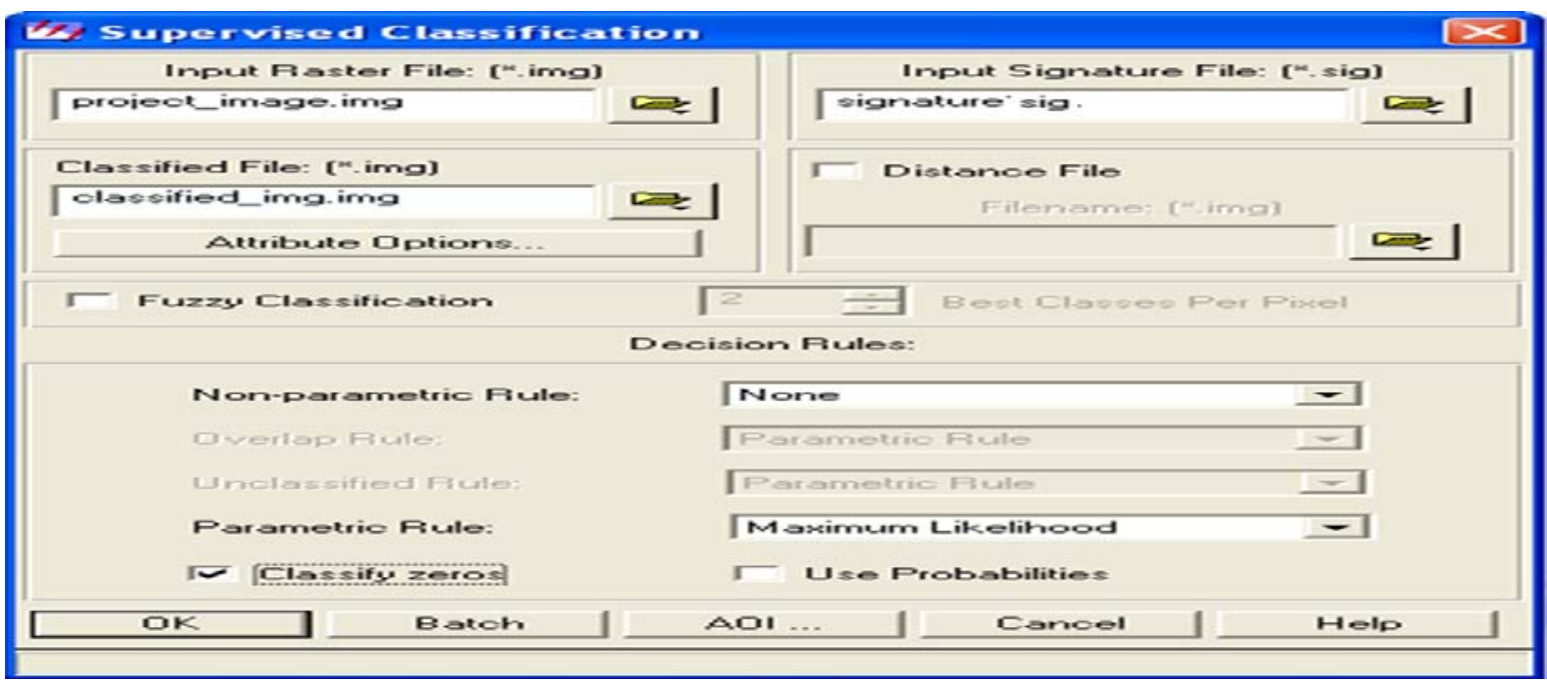


Figure 5: Supervised Classification setup

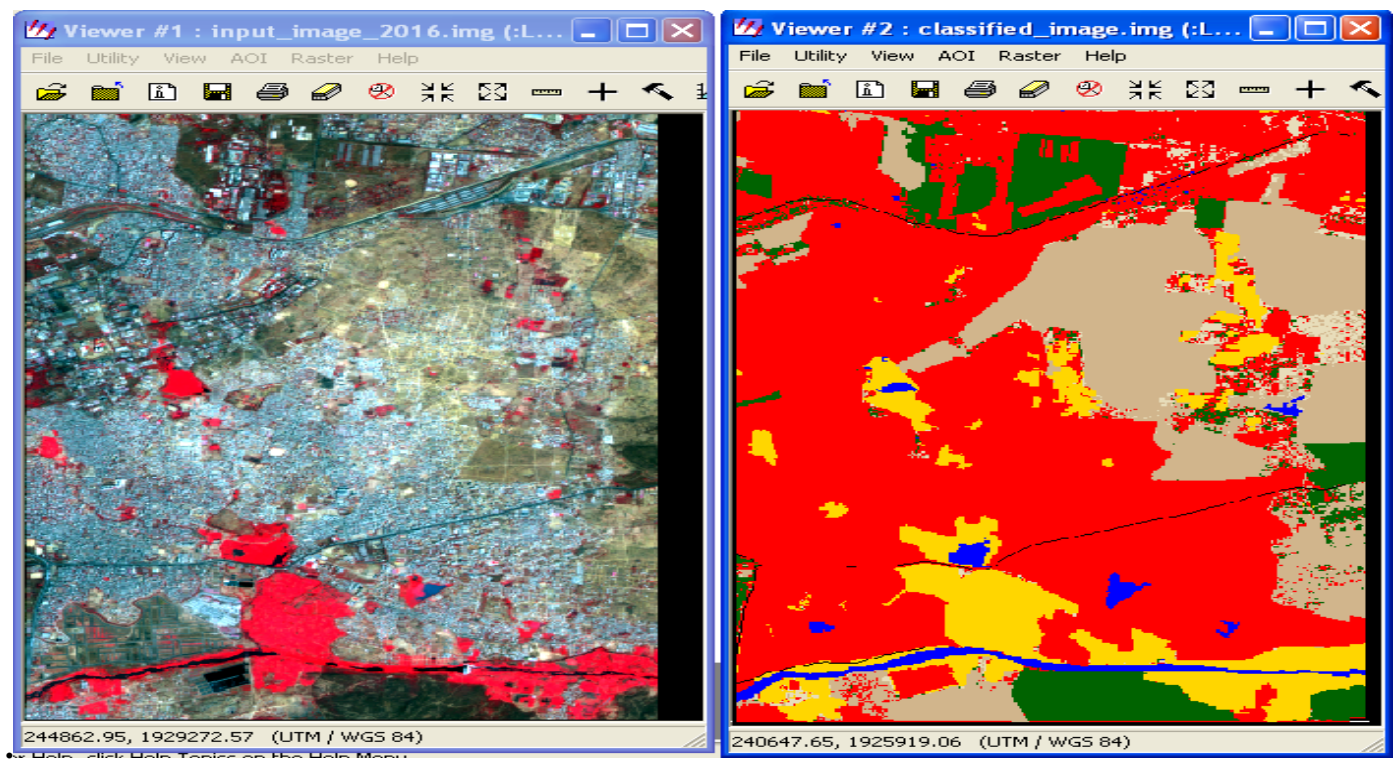

Figure 6: Original Inmage Vs Supervised Classification setup

D. RESULT ANALYSIS

\begin{tabular}{|l|l|l|l|}
\hline Class Names & Histogram & $\begin{array}{l}\text { Area } \\
\text { ha }\end{array}$ & $\begin{array}{l}\text { Area- } \\
\text { Sqmil }\end{array}$ \\
\hline Barren_Land & 422137 & 2607.81 & 4.0746985 \\
\hline Scrub_Land & 43156 & 266.6022 & 0.4165654 \\
\hline Built_Up_Land & 1271492 & 7854.82 & 12.27314 \\
\hline Agriculture_Land & 226766 & 1400.879 & 2.1888702 \\
\hline Water Bodies & 39180 & 242.0399 & 0.3781869 \\
\hline Forest Land & 177998 & 1099.608 & 1.7181346 \\
\hline Transportation & 24370 & 150.5491 & 0.2352326 \\
\hline
\end{tabular}

Tablel: Area calculations

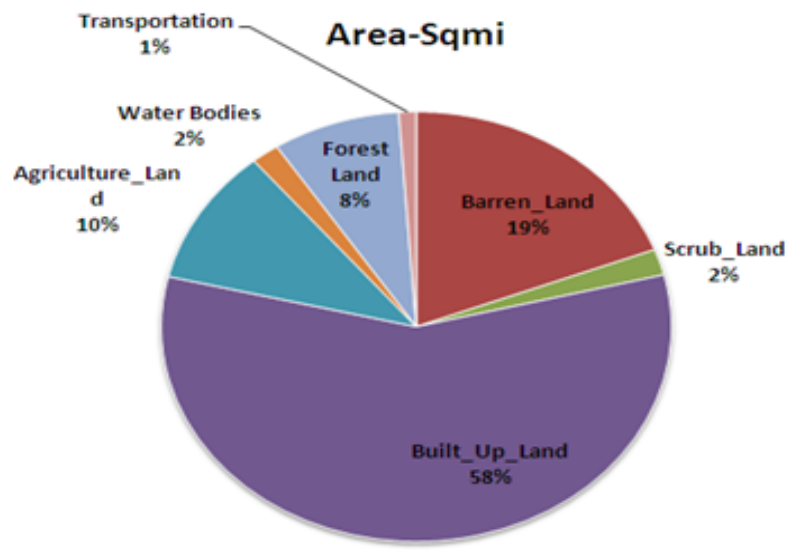

\section{E. ACCURACY ASSESSMENT}

Accuracy Report

Every care is taken to avoid overlapping of training sites by generating error matrix and transformed divergence values at each stage of classification

The overall classification accuracy of $96.0 \%$ was obtained 


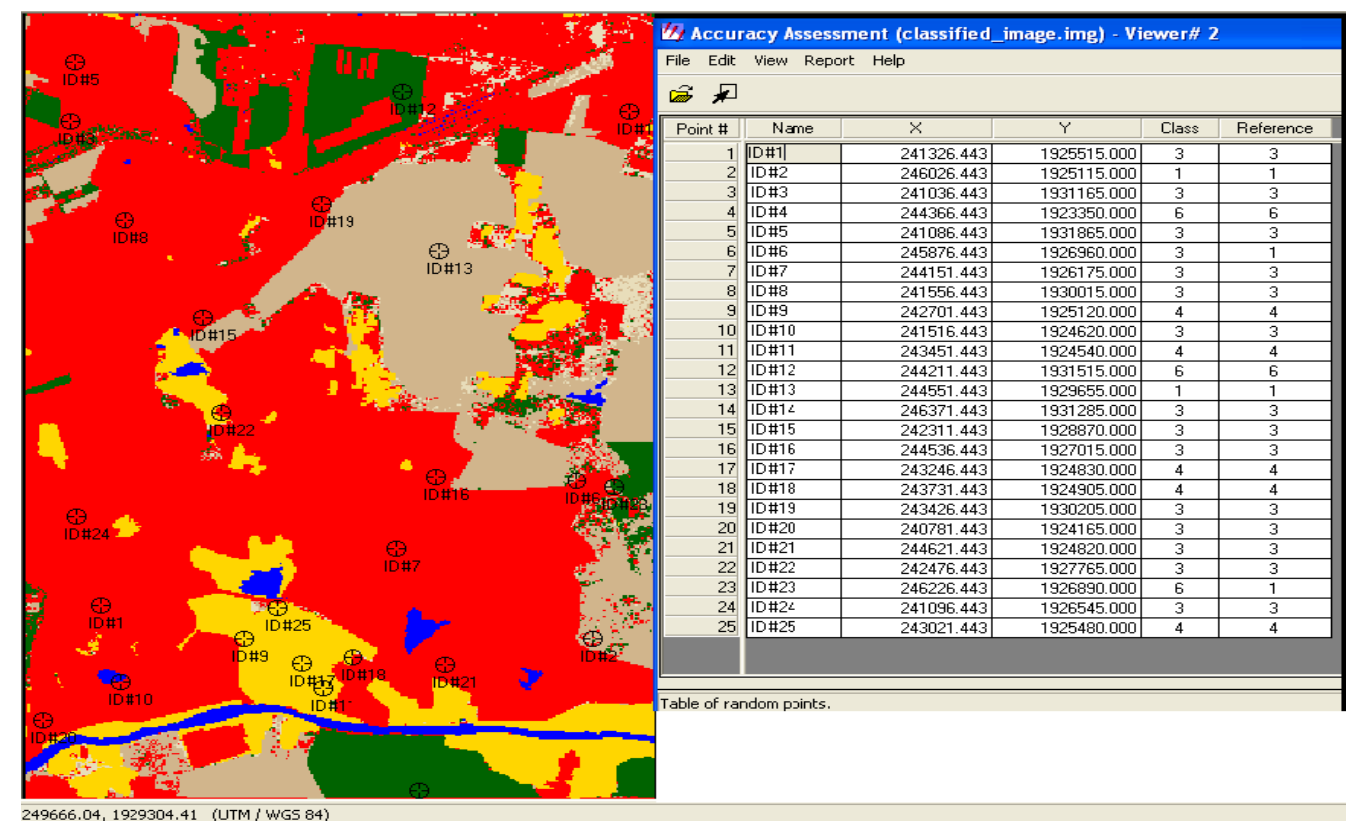

Figure7 GCP located on various class values on classified image

\section{CLASSIFICATION ACCURACY ASSESSMENT REPORT}

Image File : f:/2016-2017/project_team/classified_image.img

User Name: admin

Date $\quad$ : Wed Apr 12 20:53:09 2017

\section{ERROR MATRIX}

\section{Reference Data}

Classified Data Unclassified $\quad$ Barren_Land $\quad$ Scrub_Land Built_Up_Land

$\begin{array}{ccccc}\text { Unclassified } & 0 & 0 & 0 & 0 \\ \text { Barren_Land } & 0 & 2 & 0 & 0 \\ \text { Scrub_Land } & 0 & 0 & 0 & 0 \\ \text { Built_Up_Land } & 0 & 1 & 0 & 14 \\ \text { Agriculture_Land } & 0 & 0 & 0 & 0 \\ \text { Water Bodies } & 0 & 0 & 0 & 0 \\ \text { Forest Land } & 0 & 0 & 0 & 0 \\ \text { Transportation } & 0 & 0 & 0 & 0 \\ \text { Column Total } & 0 & 3 & 0 & 14\end{array}$


Reference Data

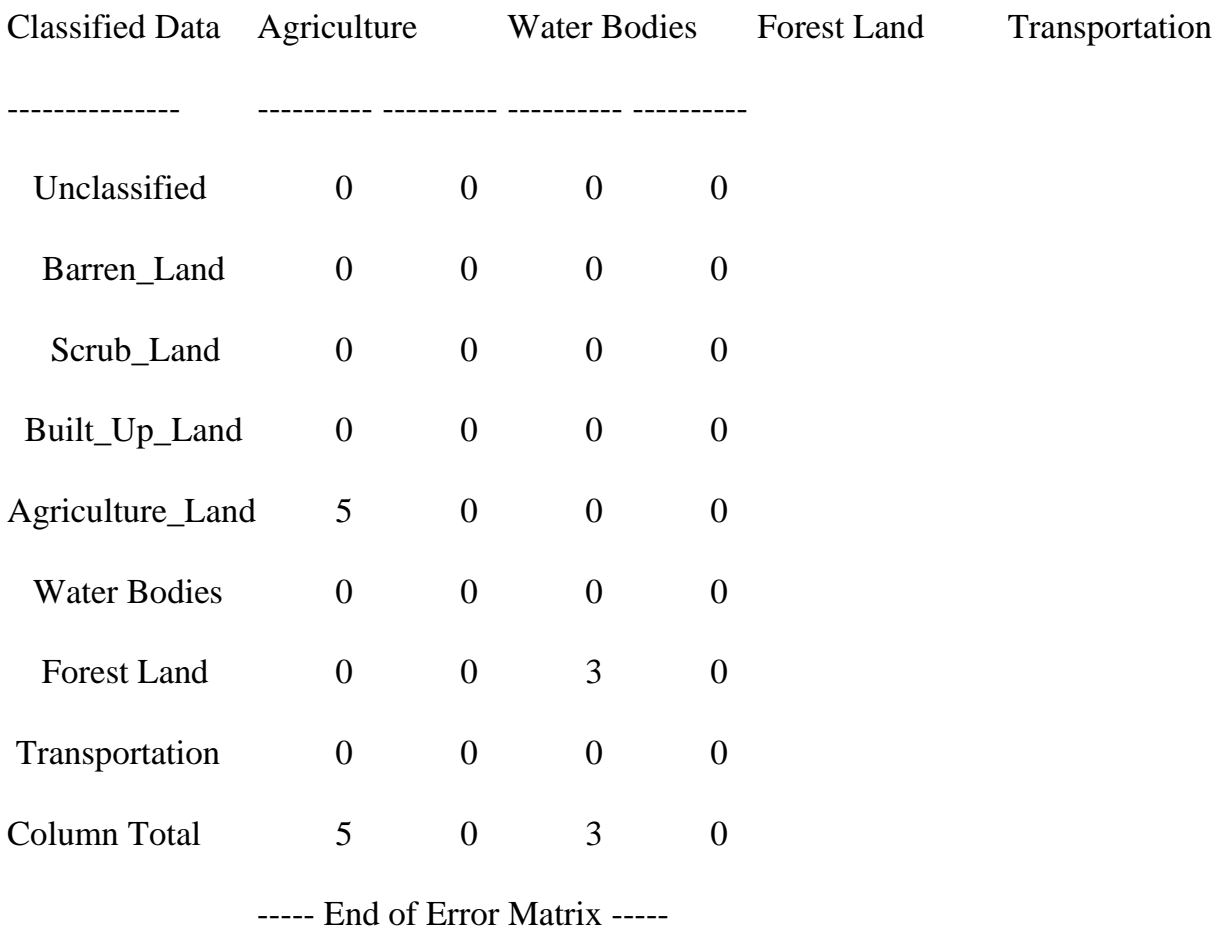

ACCURACY TOTALS

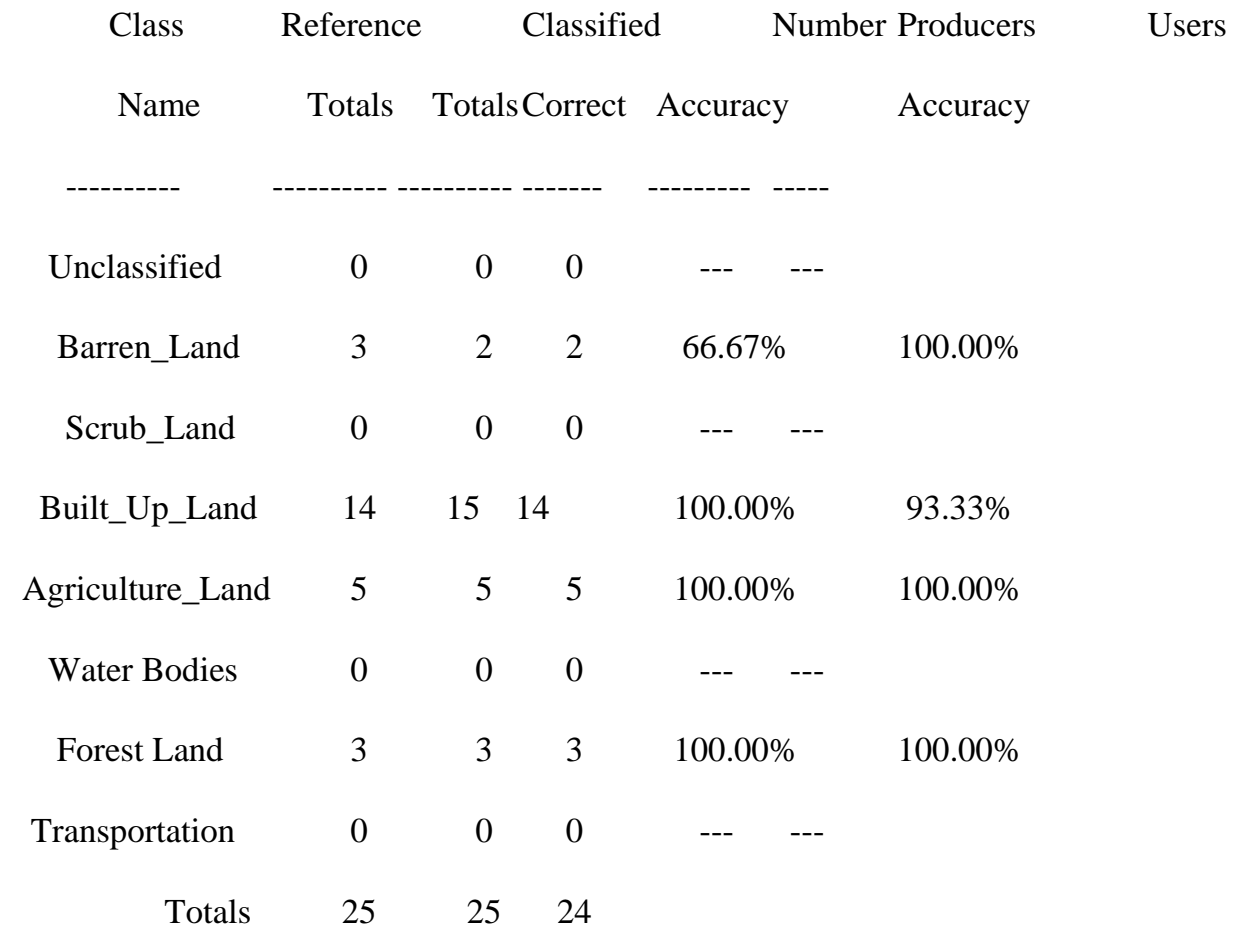

Overall Classification Accuracy $=\quad 96.00 \%$

----- End of Accuracy Totals -----

KAPPA $\left(K^{\wedge}\right)$ STATISTICS 
Overall Kappa Statistics $=0.9333$

Conditional Kappa for each Category.

$\begin{array}{cc}\text { Class Name } & \text { Kappa } \\ \text {-------- } & ---- \\ \text { Unclassified } & 0.0000 \\ \text { Barren_Land } & 1.0000 \\ \text { Scrub_Land } & 0.0000 \\ \text { Built_Up_Land } & 0.8485 \\ \text { Agriculture_Land } & 1.0000 \\ \text { Water Bodies } & 0.0000 \\ \text { Forest Land } & 1.0000 \\ \text { Transportation } & 0.0000\end{array}$

----- End of Kappa Statistics -----

\section{CONCLUSION}

- Due to increase in population and forest lands are converted into agriculture lands and over time period these agriculture lands are again converted into built up lands.

- $\quad$ Rapid industrialization, migration of population is more hence the transportation network increases.

- Based on the statistical analysis the area is calculated one can analyze \& monitor the need of water, Agriculture, forest, settlement requirement wrt increase in population

\section{REFERENCES}

[1] Menzel, W. P., and J. F. W. Purdom, Introducing GOES-I: The first of a new generation of geostationary operational environmental satellites. Bulletin of American Meteorological Society, 75(5), 757-781, 1994.

[2] Richards, J. A., Remote sensing digital image analysis: an introduction (second edition), 1993.

[3] Scorer, R. S., Cloud reflectance variations in channel-3. Int. J. Remote Sens., 10,675-686, 1989.

[4] John R. Jensen "Introductory Digital image, processing -A remote sensing perspective “ ,second edition, practice hall, Englewood cliffs New Jersey

[5] Floyd, F.Sabins Jr, “ Remote Sensing Principals And Interpretation” second edition, W.H. Freeman \& company, New York 1987

[6] ERDAS field guide, Nicki Brown and Chris Smith

[7] ERDAS IMAGINE production tour guides

[8] Interface a bulletin from NRSA data center

[9] INTERFACE -A bulletin from GIS INDIA , Hyderabad

[10] GIS handbook-by Mishra 